\title{
Progress of immune checkpoint therapy in the clinic (Review)
}

\author{
YIQUN FAN $^{1}$, CHI ZHANG ${ }^{2}$, SHENGJIE JIN $^{2}$, ZHIHUI GAO $^{2}$, JUN CAO $^{3}$, AOQING WANG $^{4}$, \\ DAWEI LI ${ }^{1}$, QIAN WANG ${ }^{2}, \mathrm{XING} \mathrm{SUN}^{5}$ and DOUSHENG BAI ${ }^{2}$ \\ ${ }^{1}$ Dalian Medical University, Dalian, Liaoning 116044; ${ }^{2}$ Department of Hepatobiliary Surgery, \\ Clinical Medical College of Yangzhou University, Yangzhou, Jiangsu 225000; \\ ${ }^{3}$ Department of Hepatobiliary Surgery, Second Xiangya Hospital of Central South University, \\ Changsha, Hunan 410011; ${ }^{4}$ Medical College of Yangzhou University, Yangzhou, Jiangsu 225001; \\ ${ }^{5}$ Institute of Hematology, Clinical Medical College of Yangzhou University, Yangzhou, Jiangsu 225000, P.R. China
}

Received July 6, 2018; Accepted October 11, 2018

DOI: $10.3892 /$ or.2018.6819

\begin{abstract}
Cancer cells can escape antitumor immune responses by exploiting inhibitory immune checkpoints. Immune checkpoint therapy, mainly including anti-CTLA-4 therapy and anti-PD-1/PD-L1 therapy, can enhance antitumor immune responses by blocking the inhibitory signals of the immune system. This therapy has produced clinical advances in a fraction of patients. Deeper insight into the tumor microenvironment and immune checkpoint inhibitors will improve this therapy. Here, we review immune checkpoint inhibitors that prevent tumor immune escape and recent clinical studies of immune checkpoint therapy. We also compare the efficacy of different combination immunotherapies, describe how the relationship between the gut microbiome and immune system can determine the therapeutic outcomes for immune checkpoint inhibitors and introduce several novel immune checkpoints that are potential targets for antitumor immunotherapy in the future.
\end{abstract}

\section{Contents}

1. Introduction

2. Mechanism of immune checkpoint therapy

3. Efficacy and the limitation of immune checkpoint therapy

4. Development of immune checkpoint therapy

5. Conclusion

Correspondence to: Dr Dousheng Bai, Department of Hepatobiliary Surgery, Clinical Medical College of Yangzhou University, 98 West Nantong Road, Yangzhou, Jiangsu 225000, P.R. China

E-mail: drbaidousheng@126.com

Key words: tumor microenvironment, immunotherapy, CTLA-4, PD-1/PD-L1, combined modality therapy, gastrointestinal microbiome

\section{Introduction}

In current cancer therapy, the limitations of traditional treatments cannot be ignored. Thus, we must explore new treatment methods. Cancer immunotherapy, which has been ignored for many years, has again become a focus of researchers and become a pillar of cancer therapy. For its outstanding efficacy, cancer immunotherapy was rated by Science as the Breakthrough of the Year in 2013 (1), and Nature considered Emily Whitehead, the first child in the world whose leukemia was treated with CAR-T therapy, to be one of 10 people who mattered in 2017 (2). As a pillar of cancer immunotherapy, immune checkpoint inhibitors have been applied in cancer therapy and have led to promising clinical responses. In this review, we discuss immune checkpoint inhibitors that prevent tumor immune escape and recent clinical studies of immune checkpoint therapy. The efficacy of combination immunotherapies and the link between the gut microbiome and immune system are also described in this review.

\section{Mechanism of immune checkpoint therapy}

Tumor microenvironment and immune checkpoint therapy. With the development of cancer research, tumors have gradually come to be regarded as complete organs rather than masses of transformed cells (3). These organs mainly include tumor cells, cancer-associated fibroblasts (CAFs), endothelial cells and immune cells. These non-cancerous cells affect the development of tumors (4). In the initial stage of tumor formation, only a small fraction of the microenvironment contains infiltrated immune cells, but eventually, various immune cells are recruited to the microenvironment and $\mathrm{T}$ cells may be the most important type of immune cell. Tumor antigens can be displayed by antigen-presenting cells (APCs), which express major histocompatibility complex (MHC) molecules on their surfaces. T cells become activated through the engagement of antigen-MHC complexes with their T cell receptors (TCRs), molecules that are mainly expressed on $\mathrm{CD} 4^{+} \mathrm{T}$ cells and $\mathrm{CD} 8^{+}$ $\mathrm{T}$ cells, after which the $\mathrm{T}$ cells proliferate and differentiate (5). Additional costimulatory signals are also required to activate 
naïve T cells. CD28 is one of the proteins expressed on T cells that acts as a B7 receptor and is constitutively expressed on naïve T cells. When CD28 binds to CD80 and CD86, two B7 molecules, costimulatory signals are provided (6). B7 molecules are only expressed by cells that can efficiently present antigens. However, tumor cells are easily overlooked by the immune system. The inflammatory response is a component of the immune system that permits antigen-presenting cells to take up tumor antigens and then present antigen-MHC complexes and permits B7 molecules to activate T cells (Fig. 1A).

Inefficient antigen presentation is an obstacle that must be overcome to allow activated $\mathrm{T}$ cells to infiltrate the tumor microenvironment. When tumor-specific $\mathrm{T}$ cells encounter tumor antigens in tumor-draining lymph nodes, an effective immune response that attacks tumor cells develops (7). Another hurdle that acts to lower the responsiveness of antitumor immunity also needs to be overcome. This hurdle is comprised of tumor cells, regulatory $\mathrm{T}$ cells, myeloid-derived suppressor cells, and other inhibitory factors in the tumor microenvironment. The accumulation of a sufficient number of obstacles that the antitumor immune response cannot develop into an effective reaction underlies this hurdle. How to eliminate the immunosuppressive state of tumors and mobilize the immune system may be the next direction of tumor immune studies.

T-cell responses and immune checkpoint therapy. How can the suppression of the antitumor immune response be weakened? Understanding the fundamental mechanisms of immune regulation in the immune system, especially in T cells, can help us solve this problem. We know that the activation of $\mathrm{T}$ cells is complex, requiring not only proliferation and functional differentiation but also attenuation and termination. In the early stages of T cell activation, a gene called CTLA-4, which has high homology to CD28, is expressed. CTLA-4 downregulates the $\mathrm{T}$ cell response by displacing CD28 costimulation (8). Researchers have proposed that the antitumor functions of $\mathrm{T}$ cells can be restored by inhibiting the binding of CTLA-4 to B7 molecules (Fig. 1B). Further animal experiments confirmed that treatment with anti-CTLA-4 antibodies in mouse tumor models enhanced the antitumor response of $\mathrm{T}$ cells $(9,10)$. Based on the data generated by experiments in mice, ipilimumab, a human anti-CTLA-4 antibody, was developed. A clinical trial indicated that patients with metastatic melanoma who were treated with ipilimumab achieved a significant improvement in overall survival (11).

The successful implementation of anti-CTLA-4 antibodies has led to a growing interest in immune checkpoint therapy (12). As research progresses, more immune checkpoints have been found. Programmed cell death-1 (PD-1), an important immune checkpoint, was discovered in 2000. PD-1 is expressed only in T cells that have been activated by antigen (13) and contributes to the inhibitory response that interferes with the function of the T-cell receptor by binding with its ligands PD-L1 and PD-L2 (14). The PD-1 expression level decreases when the activating antigen is cleared during acute responses, but its level remains high if the antigen is present for a long time (15-17). Neoantigens are one type of antigen that can cause high and sustained PD-1 expression, which is one reason cancer cells can be ignored by $\mathrm{T}$ cells $(18,19)$. PD-1 ligands (PD-L1 and PD-L2) are expressed by many cell types (such as APCs, dendritic cells, macrophages and vascular endothelial cells), but PD-L1 is the ligand that is usually expressed on cancer cells $(20,21)$. When the PD-L1 molecules on cancer cells bind with PD-1 on T cells, immunosuppression occurs (Fig. 2). Activated $\mathrm{T}$ cells will produce the cytokine interferon- $\gamma(\mathrm{IFN}-\gamma)$, which can promote the expression of PD-L1 in tumor cells (22), subsequently promoting immunosuppression. This process in normal tissues acts as a negative feedback mechanism to protect normal cells from attack by T cells. However, in tumor tissues, this mechanism leads to the tumor cells becoming invisible to the immune system. Once we have prevented PD-1 binding with its ligands, we can weaken the suppression of antitumor immunity. That is the mechanism that anti-PD-1/PD-L1 therapy is based on.

\section{Efficacy and limitations of immune checkpoint therapy}

Anti-CTLA-4 therapy. Anti-CTLA-4 antibodies, such as ipilimumab, are the pioneers of immune checkpoint blockade therapy (23). Clinical trials revealed that metastatic melanoma patients treated with ipilimumab exhibited considerable improvement in their overall survival. Based on the outstanding efficacy, ipilimumab earned FDA approval for the treatment of metastatic and non-resectable melanomas in March 2011. Four years later, ipilimumab was approved as an adjuvant therapy for stage III melanoma patients.

A multinational phase III trial was conducted with 951 patients after complete resection of stage III cutaneous melanoma. This trial demonstrated that recurrence-free survival for these patients was significantly improved by long-term treatment with a low dose of ipilimumab, but the incidence of adverse events was higher than that observed in advanced melanoma patients treated with ipilimumab (24). Secondary outcomes from this trial also revealed that health-related quality of life (HRQoL) was slightly impaired (25). The NCT00094653 trial revealed the efficacy of ipilimumab in metastatic melanoma patients. This phase III trial compared the median overall survival (OS) between ipilimumab and other treatments in metastatic melanoma patients with previous medical therapy. The results revealed that ipilimumab can improve OS in metastatic melanoma patients (ipilimumab alone vs. gp100 monotherapy: hazard ratio (HR): $0.66, P=0.003$; combination therapy vs. gp100 alone: HR: 0.68 , $\mathrm{P}<0.001)$ (11). Ipilimumab has demonstrated an antitumor effect in patients who were previously treated for melanoma and was also tested in patients without previous therapy. Another phase III trial involving 502 metastatic melanoma patients without previous therapy has been reported. This trial revealed that ipilimumab also improved OS in metastatic melanoma patients without previous therapy, and patients without previous therapy suffered no new types of adverse events compared with those in prior studies of ipilimumab (26). Aside from melanoma, ipilimumab has been studied in other diseases, such as renal cell carcinoma (27), prostate (28) and pancreatic cancer (29), but its efficacy in these solid tumors is limited (Table I). The intrinsic resistance of solid tumors, caused by features such as low tumor immunogenicity and potently immunosuppressive tumor microenvironments, can explain these results (30). 

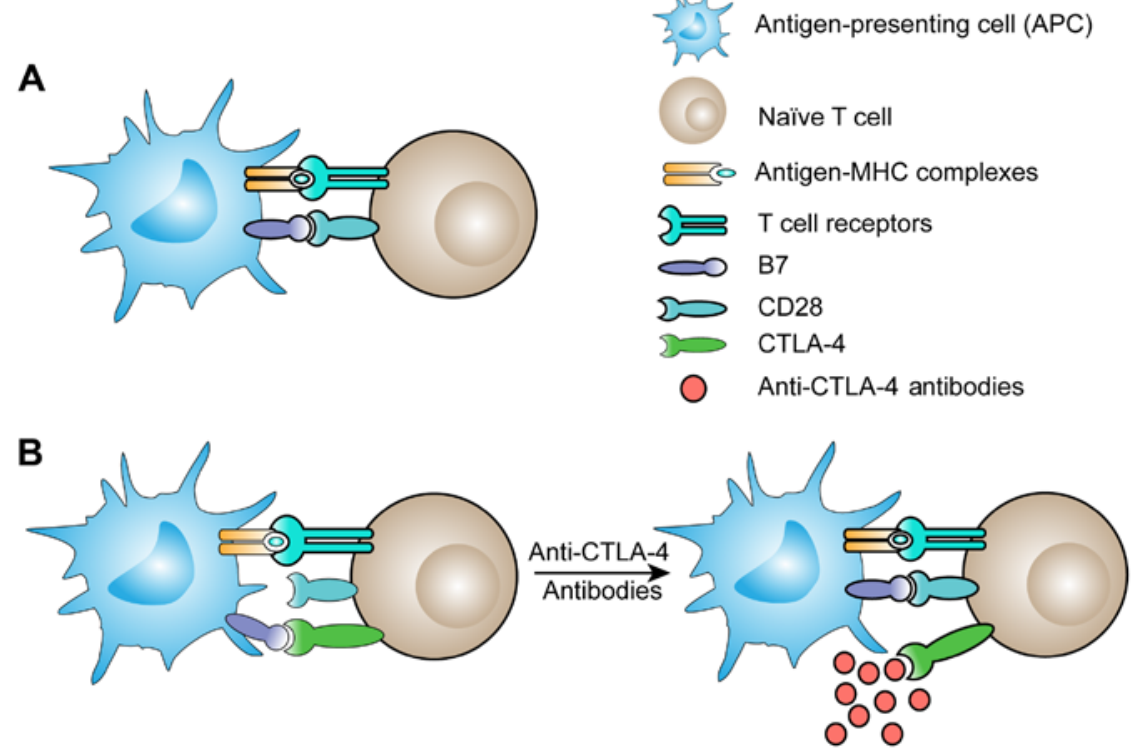

Figure 1. Mechanism of anti-CTLA-4 antibodies. (A) Naïve T cells become activated through the engagement of antigen-MHC complexes (MHC) by their T-cell receptors (TCRs). Costimulatory signals that are provided when CD28 binds to B7 are also required in this stage. (B) In the early stages of T cell activation, the T cell response can be downregulated by CTLA-4, which displaces CD28 costimulation. Anti-CTLA-4 antibodies inhibit the binding of CTLA-4 to $\mathrm{B} 7$ molecules so that $\mathrm{T}$ cells are activated normally.

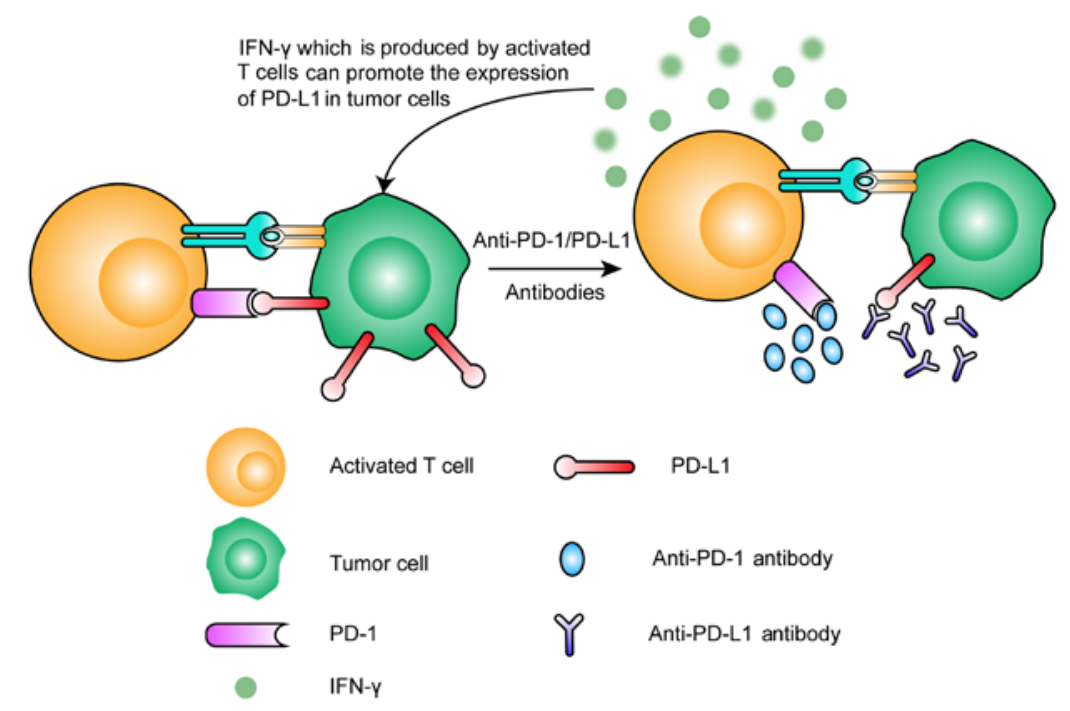

Figure 2. Mechanism of anti-PD-1/PD-L1 antibodies. PD-1 and PD-L1 are immunosuppressive at the effector T-cell stage. When PD-L1 on cancer cells binds with PD-1 on T cells, an immunosuppressive action occurs. Anti-PD-1 or PD-L1 antibodies can bind with PD-1 or PD-L1, respectively, to block their binding so that $\mathrm{T}$ cells can kill tumor cells. Activated T cells produce the cytokine interferon- $\gamma$ (IFN- $\gamma$ ), which can promote the expression of PD-L1 in tumor cells, allowing immune escape to occur.

Ipilimumab has exhibited a clear beneficial response in the clinic, but immune-related adverse events (irAEs) have become an obstacle limiting who can benefit from it. Negative regulators of immunity are important for the body to maintain immunologic homeostasis, and when they are blocked by ipilimumab, irAEs occur. The most common immune-related toxic effects that have been established include rashes, colitis, hepatitis, endocrinopathies and pneumonitis $(31,32)$. Do irAEs have an adverse impact on quality of life? A phase III trial appears to provide evidence regarding this matter (25). The results revealed that although some investigators reported grades 3-4 adverse events $(11,27)$, HRQoL showed little impairment. Nearly half of the patients withdrew from this trial due to drug-related toxic effects, which led to a significant reduction in the credibility of the trial.

It is undeniable that ipilimumab has a significant survival benefit in patients with malignant neoplasms, especially melanoma. However, adverse events and limited efficacy have ceased it from benefiting more patients. What can we do in the future to improve anti-CTLA-4 therapy? A more suitable dose can balance the efficacy and adverse events, despite $3 \mathrm{mg} / \mathrm{kg}$ being the FDA approved dose for advanced-stage disease patients. In addition, establishing a set of ipilimumab adverse reaction risk assessment systems and interventions for patients at higher risk may reduce the incidence of adverse effects. Of course, determining the resistance mechanisms to 


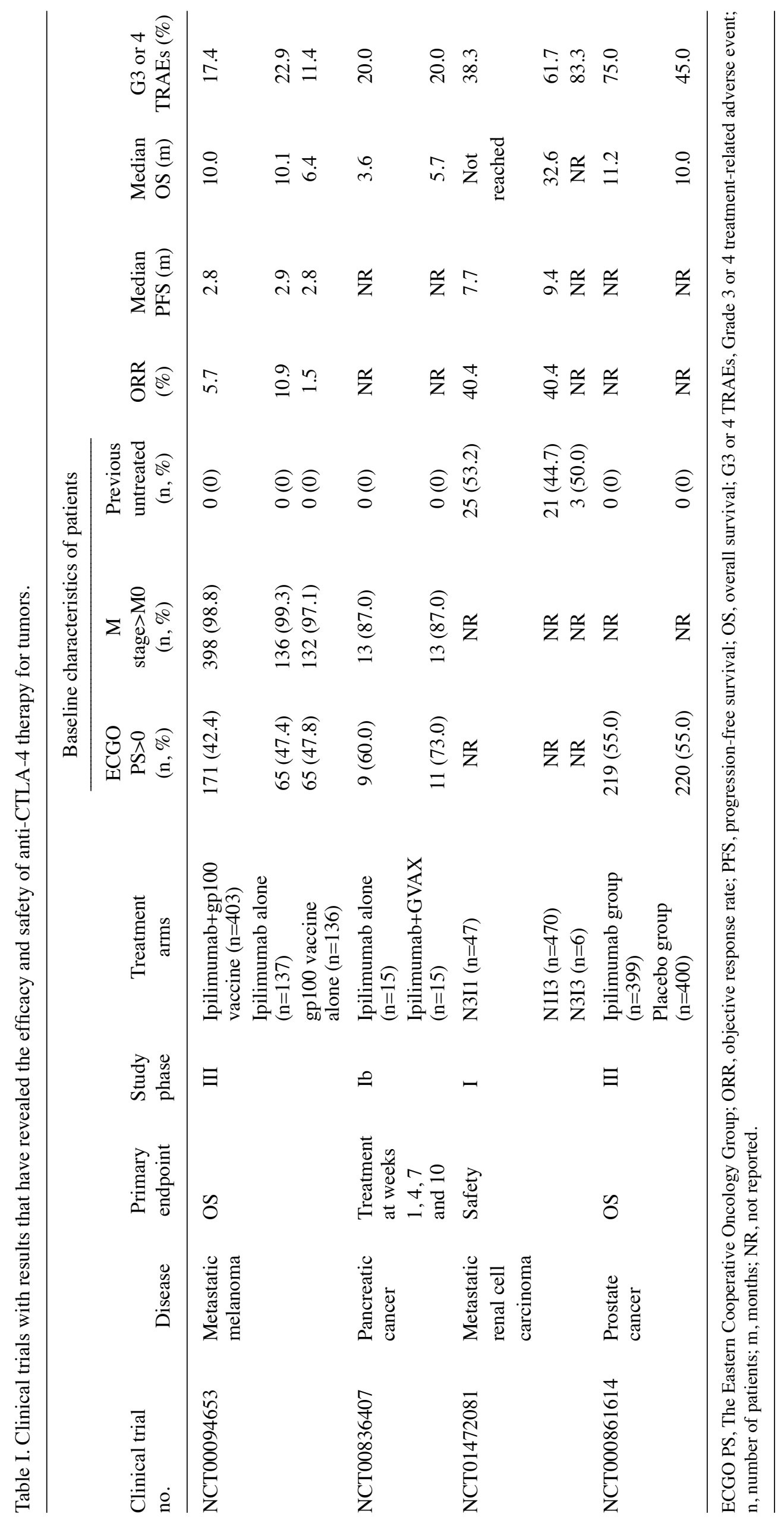


anti-CTLA-4 antibodies is also a crucial step in solving the efficacy problem.

Anti-PD-1/PD-L1 therapy. Anti-PD-1 therapy is a feasible way to relieve immunosuppression. To date, the success of this therapeutic method has been demonstrated in clinical trials. The phase Ib study NCT01953692 (33) enrolled 31 patients with classical Hodgkin lymphoma who did not respond to brentuximab vedotin therapy to receive pembrolizumab, an anti-PD-1 antibody, at a dose of $10 \mathrm{mg} / \mathrm{kg}$ every 2 weeks. The results revealed that 5 of the 20 patients who exhibited an objective response achieved complete remission, and 15 patients achieved partial remission, for an overall response rate (ORR) of $65 \%$ (90\% CI, 48-79\%). In addition to hematological tumor therapy, anti-PD-1 antibodies also play an important role in solid tumor therapy. A total of 493 patients with advanced gastric or gastro-esophageal junction cancer were enrolled in a phase III trial (NCT02267343) (34). With 8.59-8.87 months of median follow-up, the median overall survival in the nivolumab group was 1.12 months longer than the median overall survival in the placebo group (5.26 months vs. 4.14 months; HR 0.63, 95\% CI, 0.51-0.78; $\mathrm{P}<0.0001)$. The 12-month overall survival rate in the nivolumab group was $26.2 \%$ (95\% CI, 20.7-32.0), and that in the placebo group was $10.9 \%$ (95\% CI, 6.2-17.0).

Between anti-CTLA-4 antibodies and anti-PD-1 antibodies, which approach will achieve better results in patients? Interim analyses of the phase III NCT01866319 trial (35) revealed that pembrolizumab provides superior progression-free survival and overall survival vs. ipilimumab (the overall survival data remain immature; Table II). Regarding nivolumab, the NCT02388906 study demonstrated that it provided significantly longer recurrence-free survival than ipilimumab (36). In addition, both of these studies revealed that anti-PD-1 antibodies had a lower rate of serious adverse events than ipilimumab $(35,36)$.

Anti-PD-L1 therapy is another cancer treatment based on the PD-1 inhibitory pathway. In the phase II NCT02108652 trial (37), 119 patients with cisplatin-ineligible urothelial carcinoma received the anti-PD-L1 antibody atezolizumab as their first-line treatment. After a median follow-up period of 17.2 months, the ORR was $23 \%$, the complete response rate was $9 \%$, and the median overall survival was 15.9 months in all patients. In IC2/3 patients (those with PD-L1 expression on $\geq 5 \%$ of tumor-infiltrating immune cells), the ORR increased to $28 \%$. This result demonstrated the encouragingly durable activity of atezolizumab in untreated metastatic urothelial cancer patients, especially in patients with high PD-L1 expression levels. The treatment-related adverse events (TRAEs) in this trial were acceptable. Unfortunately, the results of a phase III randomized controlled study (NCT02302807) were not as ideal as those of the phase II trial $(38,39)$. The phase III study revealed that overall survival in the IC2/3 population did not differ significantly between the treatment groups (HR $0.87,95 \%$ CI $0.63-1.21, \mathrm{P}=0.41$ ), which precluded further formal statistical comparisons. The objective response rates were similar (atezolizumab vs. chemotherapy: 23 vs. $22 \%$ ), but the duration of response in the atezolizumab group was longer than that in the chemotherapy group (Table II). The reasons for these results warrant further analysis. Notably, the exploratory biomarker analysis in this study revealed that the median overall survival for patients treated with atezolizumab was numerically longer than the median overall survival for patients treated with chemotherapy in the high tumor mutation burden population (11.3 months vs. 8.3 months; HR 0.68, 95\% CI, 0.51-0.90), whereas survival was similar between the groups in the low tumor mutation burden population. Furthermore, in IC2/3 patients with a high tumor mutation burden, the median survival for the atezolizumab group was longer than that for the chemotherapy group (17.8 months vs. 10.6 months; HR $0.50,95 \%$ CI, 0.29-0.86). These results indicated that IC2/3 patients with a high tumor mutation burden will experience a significantly greater benefit from anti-PD-L1 therapy and that the level of tumor mutation burden and the PD-L1 expression level of tumor-infiltrating immune cells can be used to select a population suitable for anti-PD-L1 therapy.

Data on atezolizumab in the treatment of NSCLC have also been reported. A phase II study (40) of patients with previously treated NSCLC demonstrated the effectiveness of atezolizumab. The overall survival in the treatment group was 12.6 months, and the overall survival in the control group was 9.7 months (HR 0.73, 95\% CI, 0.53-0.99; $\mathrm{P}=0.04$ ). However, having so few patients limited the ability to draw further conclusions. Then, the phase III NCT02008227 study (41) enrolled 1,225 patients with previously treated NSCLC. As was observed in the phase II study (40), the overall survival in the treatment group was significantly prolonged. Furthermore, this study revealed that atezolizumab treatment resulted in an improvement in overall survival compared with docetaxel, regardless of PD-L1 expression levels (Table II). Overall survival improvement for patients with squamous or non-squamous histology was also analyzed, and the conclusion was similar for these 2 histology types.

Another anti-PD-L1 immune checkpoint inhibitor named avelumab has also been tested in various tumor types. The first type avelumab was tested in was metastatic Merkel cell carcinoma, which was approved by the FDA for treatment with avelumab in March 2017. The phase II trial revealed the promising efficacy of avelumab in metastatic Merkel cell carcinoma. In a cohort of 88 patients with this carcinoma, treatment with avelumab achieved objective responses in $28(31.8 \%)$ patients, and $8(28.6 \%)$ of the 28 patients achieved complete responses. In addition, responses are still ongoing in most patients who achieved an objective response, and TRAEs in this study were acceptable (42). In solid tumors, avelumab also revealed marked efficacy. A phase Ia dose-escalation trial reported that a dose of $20 \mathrm{mg} / \mathrm{kg}$ was acceptable and had no negative effect on the counts of immune cell subsets (43). In a phase Ib dose-expansion trial (44), 184 patients with NSCLC were enrolled, and 22 patients (12\%) achieved confirmed objective responses, and 92 patients $(50 \%)$ achieved disease control. The reported median OS was 8.4 months $(95 \%$ CI, 7.3-10.6) in this trial. Additionally, 23 (13\%) of the 184 patients had grade 3 or worse TRAEs. These results revealed the promising efficacy and acceptable safety of avelumab in NSCLC. However, nearly $33.2 \%$ of the enrolled patients received 2 or more previous treatments, which prevented accurate conclusions about the efficacy of avelumab. We look forward to findings from ongoing phase III trials, which will provide us with much 


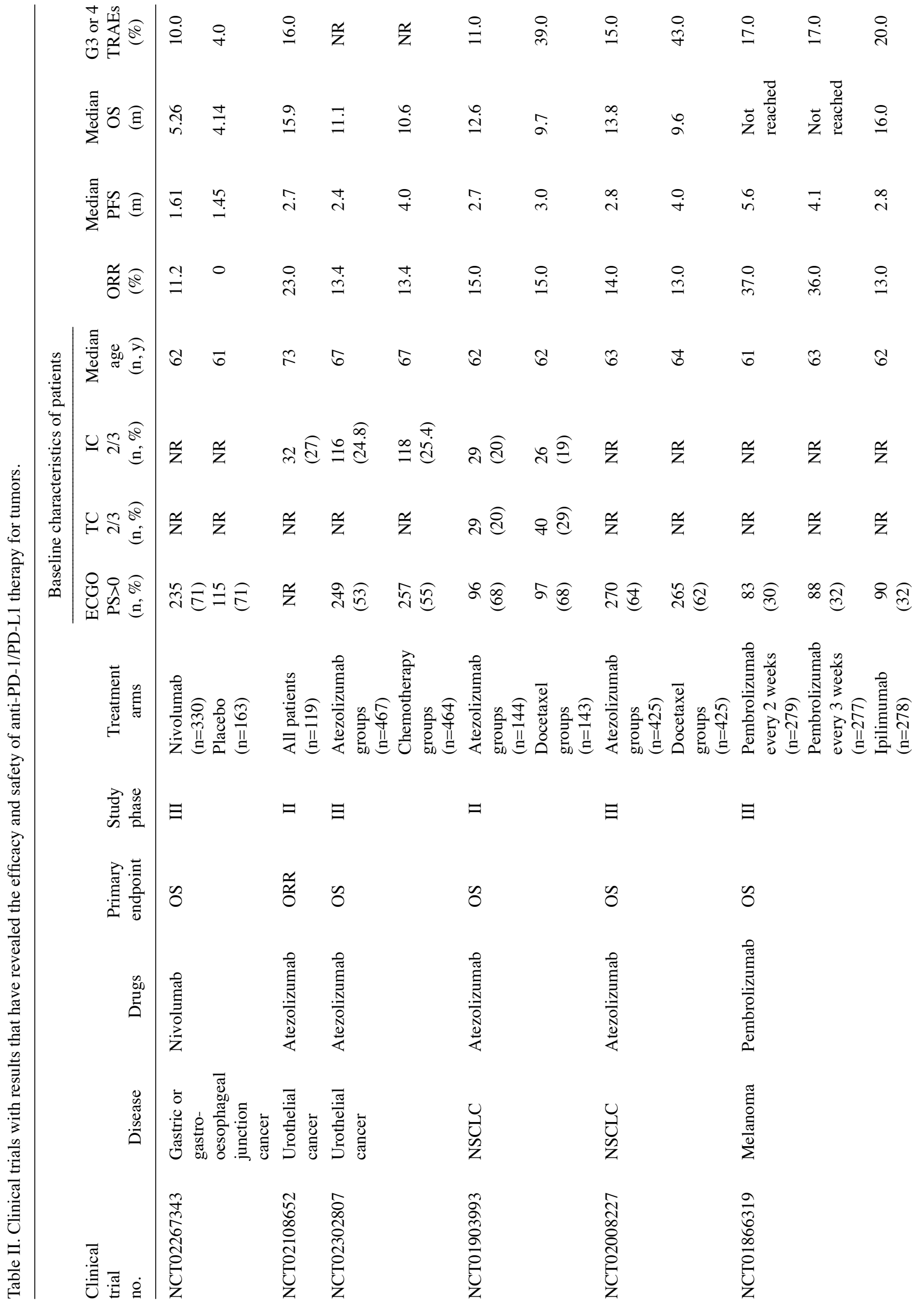


more powerful evidence. Trials with other anti-PD-L1 antibodies, such as durvalumab, have shown promising results in advanced urothelial bladder cancer and NSCLC (45-47).

Anti-PD-1/PD-L1 therapy provides a reason for us to believe that immunotherapy will achieve greater success in the future. However, in different patients, there is a great difference in the efficacy of anti-PD-1/PD-L1 therapy (48). A study performed whole exome sequencing of 35 patients with metastatic clear cell renal cell carcinoma and found that patients whose PBRM1 gene had loss-of-function mutations had significant clinical benefit from anti-PD-1/PD-L1 therapy compared to patients without loss-of-function mutations (49). This study provided a basis for selecting patients for anti-PD-1/PD-L1 therapy. Another severe problem that needs to be solved is that large numbers of patients do not show long-lasting remission. A team from the University of Pennsylvania revealed a hint to this answer. They found that using a PD-1 inhibitor in mice could restart failing $\mathrm{T}$ cells and lead to a low level of memory $\mathrm{T}$ cell development, but the restarted $\mathrm{T}$ cells failed later due to transient changes in their epigenetics (50).

Resistance to immune checkpoint blockers. Immune checkpoint blockers (ICBs), at the forefront in the field of immunotherapy, have shown enormous success in cancer therapy. Unfortunately, a large number of patients must cease their treatment. The appearance of TRAEs is an important reason for stopping treatment. However, attention should also be paid to the heterogeneity of responses to ICBs. Reported clinical data have indicated that only $10-15 \%$ of patients respond to ipilimumab therapy $(11,26)$. What has led to this phenomenon?

Tumors render immune checkpoint therapy ineffective by intrinsic and extrinsic factors. The intrinsic factors include genetic and epigenetic alterations, and presentation disrupting the action of cytotoxic T cells. Non-cancerous stromal or immune cells, an inhospitable tumor microenvironment for antitumor $\mathrm{T}$ cells, and other systemic influences (such as the gut microbiome) are considered extrinsic factors (51-53).

As the mechanisms of resistance to ICBs are further elucidated, several trials are underway to relieve the resistance. Combination therapies are in various stages of development (54), and personalized cancer vaccines hat enhance immune memory show promise (55); furthermore, biomarkers associated with resistance will be identified in additional research (53). Ultimately, clinical activity will be optimized, and the rate of clinical response will increase in the future.

\section{Development of immune checkpoint therapy}

Combination therapies of immune checkpoint inhibitors. Immune checkpoint inhibitors have achieved exciting results in some types of cancers (56-59). However, only a subset of patients benefit from immune checkpoint inhibition (60). Short-lasting remission (50) and toxic effects (61-63) are the major problems we cannot ignore. Combination anticancer therapies are useful methods to resolve these issues.

Immunotherapy shows the strongest effect on patients with small tumor burdens (64), and chemotherapy can reduce the tumor burden. Furthermore, chemotherapy can lead to tumor 
cell necrosis to expose neoantigens that potentiate the antitumor response (65). Both of these factors are advantages that support combining chemotherapy with immune checkpoint inhibitors. However, a recent clinical study on immunochemotherapy (the combination of immunotherapy and chemotherapy) did not show synergistic results (66). The median overall survival and median progression-free survival were similar in the chemotherapy plus ipilimumab group and chemotherapy plus placebo group. The number and rate of TRAEs were worse in the chemoimmunotherapy group, including higher treatment-related deaths, leading to discontinuation of the study. The toxicity profiles of the immunochemotherapy in this study were consistent with those from previous studies in melanoma (26), small cell lung cancer (67) and non-small cell lung cancer (68). All of these studies demonstrated that adverse events limit the clinical effects of immunochemotherapy. Do they prove that combined anticancer therapies are not feasible?

The answer may be yes. On T lymphocytes, both CTLA-4 and PD-1 are expressed, but their mechanisms for inhibiting the function of immune cells are different $(14,69)$. This difference provides the rationale for combination therapy. The phase III NCT01844505 study compared nivolumab alone, ipilimumab alone, and the combination of the two in advanced melanoma (70). This study found that the clinical activity of the combination therapy was better than that of either monotherapy. Health-related quality of life results from this study revealed no clinically meaningful deterioration (71). The phase I NCT01454102 trial in advanced non-small cell lung cancer revealed results analogous with NCT01844505 (72). An open-label phase Ib clinical trial observed a similar objective response rate in its pembrolizumab plus ipilimumab therapy group compared with the objective response rate in the nivolumab plus ipilimumab therapy group in the NCT01844505 study (61 vs. 58\%) (70,73).

In addition, according to previous studies, combination with radiotherapy or targeted therapy enhanced the anticancer effect of immune checkpoint inhibition (74,75). Another powerful combination strategy that combines oncolytic viruses with immune checkpoint inhibitors has been studied in phase Ib and phase II trials $(76,77)$. Both trials indicated that this combination strategy had greater antitumor activity vs. monotherapy. In addition, the incidence of TRAEs was acceptable. Further clinical trials using combination anticancer therapies are underway, and the current results show promise that these therapies will reveal more in the future.

Gut microbiome and immune checkpoint therapy. The gut microbiome, which includes bacteria, microbial eukaryotes, and viruses, lives in the human intestine (78). Its composition and status are closely related to the health of the host (79) and to the outcome of cancer immunotherapy (80).

The ability of intestinal microbiota to modulate the response to immune checkpoint inhibitors was revealed by preclinical studies. A study in mice revealed that commensal Bifidobacterium in the intestine promoted antitumor immunity and anti-PD-L1 efficacy (81). Melanoma growth in mice harboring distinct commensal microbiota was compared in this study, and it was found that spontaneous antitumor immunity varied. In addition, inoculated Bifidobacterium in intestines facilitated the curative effect of anti-PD-L1 therapy, enhancing the number of $\mathrm{CD}^{+} \mathrm{T}$ cells. Another study in mice demonstrated that gut microbiota directly affected anti-CTLA-4 antibody efficacy (82).

Preclinical studies indicated that immune checkpoint inhibitors rely on the gut microbiome in mice. Does this also occur in humans? Clinical data from patients with epithelial tumors were analyzed (83). The results revealed a shorter median overall survival in patients who used antibiotics before or at the beginning of anti-PD-1 therapy, which meant that intestinal flora disorder inhibited the clinical benefit of immune checkpoint inhibitors. This inhibitory effect is due to the lack of Akkermansia muciniphila in this study, and this type of bacteria can increase the recruitment of $\mathrm{CD}^{+} \mathrm{T}$ cells into the tumor microenvironment by producing interleukin-12, which promotes antitumor activities (83). Two additional studies focused on melanoma. These studies demonstrated that greater diversity in the gut microbiomes of melanoma patients led to better clinical effects. Furthermore, responding patients had a higher abundance of bacterial species, including Ruminococcaceae, Bifidobacterium longum, Collinsella aerofaciens and Enterococcus faecium $(84,85)$.

The gut microbiome is similar to a treasure trove for next-generation medicine (86). Combination therapy that combines the microbiota with immune checkpoint inhibitors will provide more possibilities for the development of precision medicine for cancer in the future.

New immune checkpoints. In addition to CTLA-4 and PD-1/PD-L1, several new immune checkpoints have emerged. The tumor glyco-code as a novel immune checkpoint should not be overlooked (87). Several studies have shown that the tumor glyco-code modifies immunity by affecting lectin receptors expressed by immune cells. For example, Tn antigen (one of the most common tumor-associated glycans) drives an immune suppressive program in macrophages by enriching for molecules (such as MUC1, CD43 and CD45) that interact with macrophage galactose-specific lectin (MGL) on macrophages. This program is characterized by the induction of effector $\mathrm{T}$ cell apoptosis and upregulation of IL-10 $(88,89)$. Altered glycosylation of malignant cells often occurs in the early stages of malignant transformation, and different types of cancer have been marked by certain tumor-associated glycans, making the early diagnosis of cancer possible (90-92). Monoclonal antibodies can be used to characterize changes in the tumor glyco-code that serve as cancer biomarkers $(93,94)$, and the expression statuses of glycan and lectin synthesis genes could serve as novel diagnostic tools or prognostic predictors $(95,96)$. Notably, the tumor glyco-code can be harnessed not only for cancer diagnosis but also for cancer therapy. Several therapies based on the tumor glyco-code have been developed, such as anti-glycan vaccines, inhibitors capable of blocking glycan-lectin interactions, new tumor glyco-specific CAR-T cells and dendritic cell targeting (97-100). We can predict that the development of research on the tumor glyco-code will benefit patients who fail to respond to current immunotherapy regimens.

Another novel immune checkpoint that should be focused on is T-cell immunoglobulin mucin 3 (TIM-3)/galectin-9. TIM-3 and its ligand galectin-9 play important roles in tumor-associated immune suppression $(101,102)$. Initial 
evidence has revealed that interactions between these proteins induce negative regulation of the Th1 and Th17 responses $(103,104)$. Further studies revealed that $\mathrm{CD}^{+}$ $\mathrm{T}$ cells, which are the most suppressed population, are marked by TIM-3 in preclinical cancer models. The TIM-3 pathway together with the PD-1 pathway may promote a more severe dysfunctional phenotype than the TIM-3 pathway by itself in $\mathrm{CD}^{+} \mathrm{T}$ cells of malignant tumors (105). In addition, other studies have reported that TIM-3 plays a crucial role in the biology of Tregs in tumors. In preclinical models, compared with TIM-3- Tregs, TIM-3 ${ }^{+}$Tregs have been revealed to be more immunosuppressive in the tumor tissue, which is likely due to increased levels of IL-10 and other key effector molecules, including perforin and granzymes (106). Based on these studies, TIM3 can be regarded as a target for immunotherapy. Preclinical studies have revealed very promising results for TIM-3 blockade in colon carcinoma, Wilms tumor and prostate cancer (107). Notably, better effectiveness has been demonstrated when TIM-3 blockade is combined with PD-1 blockade, but the molecular mechanisms of these effects have not been elucidated $(104,108)$. The ligand galectin-9 also plays a role in preventing cancer progression and immune escape. In breast cancer cells, galectin-9, which exists in the cytoplasm, induces cancer cell aggregation and prevents tumor metastasis (109). In addition, galectin-9 induced apoptosis and inhibited the growth of hepatocellular carcinoma cells in an in vivo study (110). Synthetic galectin-9 has been demonstrated to be effective without significant side effects in mice (111), but it remains to be investigated in humans. Galectin- 9 may be a potential antitumor agent but requires thorough investigation in the future (112).

\section{Conclusion}

An immune checkpoint is a protective factor that prevents healthy cells from damage caused by excessive $\mathrm{T}$ cell activity. Tumor cells use this mechanism to suppress immune cells and escape from the body's immune system. Immune checkpoint inhibitors can relieve this inhibitory effect and reactivate $\mathrm{T}$ cells to destroy cancer cells.

Anti-CTLA-4 antibodies and anti-PD-1/PD-L1 antibodies have revealed encouraging results in a broad range of tumors, but these therapies do not achieve objective responses in every patient. Furthermore, some responding patients have to discontinue these treatments due to serious treatment-related adverse effects. In addition, some patients are resistant to ICBs and fail to achieve long-lasting remission. All of these problems are urging researchers to determine a certain standard with which to select more suitable patients for immune checkpoint inhibition. Recent studies have indicated that patients with a higher tumor mutation burden and higher PD-L1 expression exhibit better clinical effects. Combination anticancer therapy is a new approach that combines the benefits of different cancer treatments. Choosing the right combination of agents at the right dose is essential for benefiting more patients. Consideration of the gut microbiome with immune checkpoint inhibitors is another therapeutic method for anticancer therapy. A high abundance of bacterial species in the intestine leads to better clinical effects. Inoculation of specific microbial species can improve the effect of immunotherapy in mice. The excellent results in animal experiments have made us excited about the effect of this treatment in humans. Several new immune checkpoints have been found. Research targeting these checkpoints in antitumor therapies is underway. We believe that inhibitors of these checkpoints will be anticancer agents in the future following a thorough investigation. As immune checkpoint therapies are developed, more patients will experience benefits.

\section{Acknowledgements}

YF especially wishes to thank Xiaoming Fan (Hengdian Thermal Electricity Co., Ltd, Jinhua, China) and Jinyun Lu (Dongxin Wushu School, Jinhua, China) who have given him powerful spiritual support over the past decades.

\section{Funding}

This study was supported by the National Nature Science Foundation of China (grant no. 81702861).

\section{Availability of data and materials}

The datasets used during the present study are available from the corresponding author upon reasonable request.

\section{Authors' contributions}

YF, CZ, SJ and DB conceived and designed the study. YF, AW, JC, DL and QW researched the literature. YF and CZ performed the analysis of data and drafted the manuscript. YF, ZG, XS and JC jointly designed the figures. YF, CZ, SJ, ZG, JC, AW, DL, QW, XS and DB critically revised the article for important intellectual content. All authors read and approved the manuscript and agree to be accountable for all aspects of the research in ensuring that the accuracy or integrity of any part of the work are appropriately investigated and resolved.

\section{Ethics approval and consent to participate}

Not applicable.

\section{Patient consent for publication}

Not applicable.

\section{Competing interests}

The authors declare that they have no competing interests.

\section{References}

1. McNutt M: Cancer immunotherapy. Science 342: 1417, 2013.

2. Ledford H: Engineered cell therapy for cancer gets thumbs up from FDA advisers. Nature 547: 270, 2017.

3. Junttila MR and de Sauvage FJ: Influence of tumour micro-environment heterogeneity on therapeutic response. Nature 501: 346-354, 2013.

4. Nagarsheth N, Wicha MS and Zou W: Chemokines in the cancer microenvironment and their relevance in cancer immunotherapy. Nat Rev Immunol 17: 559-572, 2017. 
5. Church SE and Galon J: Tumor microenvironment and immunotherapy: The whole picture is better than a glimpse. Immunity 43 : 631-633, 2015.

6. Greenwald RJ, Freeman GJ and Sharpe AH: The B7 family revisited. Annu Rev Immunol 23: 515-548, 2005.

7. Swartz MA and Lund AW: Lymphatic and interstitial flow in the tumour microenvironment: Linking mechanobiology with immunity. Nat Rev Cancer 12: 210-219, 2012

8. Linsley PS, Brady W, Urnes M, Grosmaire LS, Damle NK and Ledbetter JA: CTLA-4 is a second receptor for the B cell activation antigen B7. J Exp Med 174: 561-569, 1991.

9. Leach DR, Krummel MF and Allison JP: Enhancement of antitumor immunity by CTLA-4 blockade. Science 271: 1734-1736, 1996.

10. Zamarin D, Holmgaard RB, Subudhi SK, Park JS, Mansour M Palese P, Merghoub T, Wolchok JD and Allison JP: Localized oncolytic virotherapy overcomes systemic tumor resistance to immune checkpoint blockade immunotherapy. Sci Transl Med 6 : 226ra32, 2014

11. Hodi FS, O'Day SJ, McDermott DF, Weber RW, Sosman JA, Haanen JB, Gonzalez R, Robert C, Schadendorf D, Hassel JC, et al: Improved survival with ipilimumab in patients with metastatic melanoma. N Engl J Med 363: 711-723, 2010.

12. Pardoll DM: The blockade of immune checkpoints in cancer immunotherapy. Nat Rev Cancer 12: 252-264, 2012.

13. Agata Y, Kawasaki A, Nishimura H, Ishida Y, Tsubata T, Yagita $\mathrm{H}$ and Honjo T: Expression of the PD-1 antigen on the surface of stimulated mouse T and B lymphocytes. Int Immunol 8: 765-772, 1996.

14. Wei SC, Levine JH, Cogdill AP, Zhao Y, Anang NAS Andrews MC, Sharma P, Wang J, Wargo JA, Pe'er D, et al: Distinct cellular mechanisms underlie anti-CTLA-4 and anti-PD-1 checkpoint blockade. Cell 170: 1120-1133.e17, 2017.

15. Pauken KE and Wherry EJ: Overcoming T cell exhaustion in infection and cancer. Trends Immunol 36: 265-276, 2015.

16. Barber DL, Wherry EJ, Masopust D, Zhu B, Allison JP, Sharpe AH, Freeman GJ and Ahmed R: Restoring function in exhausted CD8 T cells during chronic viral infection. Nature 439: 682-687, 2006.

17. Crawford A, Angelosanto JM, Kao C, Doering TA, Odorizzi PM, Barnett BE and Wherry EJ: Molecular and transcriptional basis of $\mathrm{CD} 4^{+} \mathrm{T}$ cell dysfunction during chronic infection. Immunity 40 289-302, 2014

18. Restifo NP, Smyth MJ and Snyder A: Acquired resistance to immunotherapy and future challenges. Nat Rev Cancer 16 : 121-126, 2016

19. Chen DS and Mellman I: Elements of cancer immunity and the cancer-immune set point. Nature 541: 321-330, 2017.

20. Sharpe AH and Pauken KE: The diverse functions of the PD1 inhibitory pathway. Nat Rev Immunol 18: 153-167, 2017

21. Ribas A and Hu-Lieskovan S: What does PD-L1 positive or negative mean? J Exp Med 213: 2835-2840, 2016.

22. Dong H, Strome SE, Salomao DR, Tamura H, Hirano F, Flies DB, Roche PC, Lu J, Zhu G, Tamada K, et al: Tumor-associated B7-H1 promotes T-cell apoptosis: A potential mechanism of immune evasion. Nat Med 8: 793-800, 2002

23. Sharma P, Hu-Lieskovan S, Wargo JA and Ribas A: Primary, adaptive, and acquired resistance to cancer immunotherapy. Cell 168: 707-723, 2017.

24. Eggermont AM, Chiarion-Sileni V, Grob JJ, Dummer R, Wolchok JD, Schmidt H, Hamid O, Robert C, Ascierto PA, Richards JM, et al: Adjuvant ipilimumab versus placebo after complete resection of high-risk stage III melanoma (EORTC 18071): A randomised, double-blind, phase 3 trial. Lancet Oncol 16: 522-530, 2015.

25. Coens C, Suciu S, Chiarion-Sileni V, Grob JJ, Dummer R, Wolchok JD, Schmidt H, Hamid O, Robert C, Ascierto PA, et al Health-related quality of life with adjuvant ipilimumab versus placebo after complete resection of high-risk stage III melanoma (EORTC 18071): Secondary outcomes of a multinational, randomised, double-blind, phase 3 trial. Lancet Oncol 18: 393-403, 2017

26. Robert C, Thomas L, Bondarenko I, O'Day S, Weber J, Garbe C, Lebbe C, Baurain JF, Testori A, Grob JJ, et al: Ipilimumab plus dacarbazine for previously untreated metastatic melanoma. $\mathrm{N}$ Engl J Med 364: 2517-2526, 2011.

27. Hammers HJ, Plimack ER, Infante JR, Rini BI, McDermott DF, Lewis LD, Voss MH, Sharma P, Pal SK, Razak ARA, et al: Safety and efficacy of nivolumab in combination with ipilimumab in metastatic renal cell carcinoma: The CheckMate 016 Study. J Clin Oncol 35: 3851-3858, 2017.
28. Kwon ED, Drake CG, Scher HI, Fizazi K, Bossi A, Van den Eertwegh AJ, Krainer M, Houede N, Santos R, Mahammedi H, et al; CA184-043 Investigators: Ipilimumab versus placebo after radiotherapy in patients with metastatic castration-resistant prostate cancer that had progressed after docetaxel chemotherapy (CA184-043): A multicentre, randomised, double-blind, phase 3 trial. Lancet Oncol 15: 700-712, 2014.

29. Le DT, Lutz E, Uram JN, Sugar EA, Onners B, Solt S, Zheng L, Diaz LA Jr, Donehower RC, Jaffee EM, et al: Evaluation of ipilimumab in combination with allogeneic pancreatic tumor cells transfected with a GM-CSF gene in previously treated pancreatic cancer. J Immunother. 36: 382-389, 2013.

30. Zhao X and Subramanian S: Intrinsic resistance of solid tumors to immune checkpoint blockade therapy. Cancer Res 77: 817-822, 2017.

31. Friedman CF, Proverbs-Singh TA and Postow MA: Treatment of the immune-related adverse effects of immune checkpoint inhibitors: A review. JAMA Oncol 2: 1346-1353, 2016.

32. Cousin S, Seneschal J and Italiano A: Toxicity profiles of immunotherapy. Pharmacol Ther 181: 91-100, 2018.

33. Armand P, Shipp MA, Ribrag V, Michot JM, Zinzani PL, Kuruvilla J, Snyder ES, Ricart AD, Balakumaran A, Rose S, et al: Programmed death-1 blockade with pembrolizumab in patients with classical Hodgkin lymphoma after brentuximab vedotin failure. J Clin Oncol 34: 3733-3739, 2016.

34. Kang YK, Boku N, Satoh T, Ryu MH, Chao Y, Kato K, Chung HC, Chen JS, Muro K, Kang WK, et al: Nivolumab in patients with advanced gastric or gastro-oesophageal junction cancer refractory to, or intolerant of, at least two previous chemotherapy regimens (ONO-4538-12, ATTRACTION-2): A randomised, double-blind, placebo-controlled, phase 3 trial. Lancet 390: 2461-2471, 2017.

35. Schachter J, Ribas A, Long GV, Arance A, Grob JJ, Mortier L, Daud A, Carlino MS, McNeil C, Lotem M, et al: Pembrolizumab versus ipilimumab for advanced melanoma: Final overall survival results of a multicentre, randomised, open-label phase 3 study (KEYNOTE-006). Lancet 390: 1853-1862, 2017.

36. Weber J, Mandala M, Del Vecchio M, Gogas HJ, Arance AM, Cowey CL, Dalle S, Schenker M, Chiarion-Sileni V, Marquez-Rodas I, et al; CheckMate 238 collaborators: Adjuvant nivolumab versus ipilimumab in resected stage III or IV melanoma. N Engl J Med 377: 1824-1835, 2017.

37. Balar AV, Galsky MD, Rosenberg JE, Powles T, Petrylak DP, Bellmunt J, Loriot Y, Necchi A, Hoffman-Censits J, Perez-Gracia JL, et al: IMvigor210 Study Group: Atezolizumab as first-line treatment in cisplatin-ineligible patients with locally advanced and metastatic urothelial carcinoma: A single-arm, multicentre, phase 2 trial. Lancet 389: 67-76, 2017.

38. Powles T, Durán I, van der Heijden MS, Loriot Y, Vogelzang NJ, De Giorgi U, Oudard S, Retz MM, Castellano D, Bamias A, et al: Atezolizumab versus chemotherapy in patients with platinum-treated locally advanced or metastatic urothelial carcinoma (IMvigor211): A multicentre, open-label, phase 3 randomised controlled trial. Lancet 391: 748-757, 2018.

39. Rosenberg JE, Hoffman-Censits J, Powles T, van der Heijden MS, Balar AV, Necchi A, Dawson N, O'Donnell PH, Balmanoukian A, Loriot Y, et al: Atezolizumab in patients with locally advanced and metastatic urothelial carcinoma who have progressed following treatment with platinum-based chemotherapy: A single-arm, multicentre, phase 2 trial. Lancet 387: 1909-1920, 2016.

40. Fehrenbacher L, Spira A, Ballinger M, Kowanetz M, Vansteenkiste J, Mazieres J, Park K, Smith D, Artal-Cortes A, Lewanski $\mathrm{C}$, et al; POPLAR study group: Atezolizumab versus docetaxel for patients with previously treated non-small-cell lung cancer (POPLAR): A multicentre, open-label, phase 2 randomised controlled trial. Lancet 387: 1837-1846, 2016.

41. Rittmeyer A, Barlesi F, Waterkamp D, Park K, Ciardiello F Von Pawel J, Gadgeel SM, Hida T, Kowalski DM, Dols MC, et al; OAK study group: Atezolizumab versus docetaxel in patients with previously treated non-small-cell lung cancer (OAK): A phase 3, open-label, multicentre randomised controlled trial. Lancet 389: 255-265, 2017.

42. Kaufman HL, Russell J, Hamid O, Bhatia S, Terheyden P, D'Angelo SP, Shih KC, Lebbé C, Linette GP, Milella M, et al: Avelumab in patients with chemotherapy-refractory metastatic Merkel cell carcinoma: A multicentre, single-group, open-label, phase 2 trial. Lancet Oncol 17: 1374-1385, 2016.

43. Heery CR, O'Sullivan-Coyne G, Madan RA, Cordes L, Rajan A, Rauckhorst M, Lamping E, Oyelakin I, Marté JL, Lepone LM, et al: Avelumab for metastatic or locally advanced previously treated solid tumours (JAVELIN Solid Tumor): A phase 1a, multicohort, dose-escalation trial. Lancet Oncol 18: 587-598, 2017. 
44. Gulley JL, Rajan A, Spigel DR, Iannotti N, Chandler J, Wong DJL, Leach J, Edenfield WJ, Wang D, Grote HJ, et al: Avelumab for patients with previously treated metastatic or recurrent non-small-cell lung cancer (JAVELIN Solid Tumor) Dose-expansion cohort of a multicentre, open-label, phase $1 \mathrm{~b}$ trial. Lancet Oncol 18: 599-610, 2017.

45. Antonia SJ, Villegas A, Daniel D, Vicente D, Murakami S, Hui R, Yokoi T, Chiappori A, Lee KH, De Wit M, et al; PACIFIC Investigators: Durvalumab after chemoradiotherapy in stage II non-small-cell lung cancer. N Engl J Med 377: 1919-1929, 2017.

46. Massard C, Gordon MS, Sharma S, Rafii S, Wainberg ZA, Luke J, Curiel TJ, Colon-Otero G, Hamid O, Sanborn RE, et al: Safety and efficacy of durvalumab (MEDI4736), an anti-programmed cell death ligand-1 immune checkpoint inhibitor, in patients with advanced urothelial bladder cancer. J Clin Oncol 34: 3119-3125, 2016.

47. Garassino MC, Cho BC, Kim JH, Mazières J, Vansteenkiste J, Lena H, Corral Jaime J, Gray JE, Powderly J, Chouaid C, et al ATLANTIC investigators: Durvalumab as third-line or later treatment for advanced non-small-cell lung cancer (ATLANTIC) An open-label, single-arm, phase 2 study. Lancet Oncol 19: 521-536, 2018.

48. Luke JJ, Flaherty KT, Ribas A and Long GV: Targeted agents and immunotherapies: Optimizing outcomes in melanoma. Nat Rev Clin Oncol 14: 463-482, 2017

49. Miao D, Margolis CA, Gao W, Voss MH, Li W, Martini DJ, Norton C, Bossé D, Wankowicz SM, Cullen D, et al: Genomic correlates of response to immune checkpoint therapies in clear cell renal cell carcinoma. Science 359: 801-806, 2018.

50. Pauken KE, Sammons MA, Odorizzi PM, Manne S, Godec J, Khan O, Drake AM, Chen Z, Sen DR, Kurachi M, et al: Epigenetic stability of exhausted $\mathrm{T}$ cells limits durability of reinvigoration by PD-1 blockade. Science 354: 1160-1165, 2016.

51. Pitt JM, Vétizou M, Daillère R, Roberti MP, Yamazaki T, Routy B, Lepage P, Boneca IG, Chamaillard M, Kroemer G, et al: Resistance mechanisms to immune-checkpoint blockade in cancer: Tumor-intrinsic and -extrinsic factors. Immunity 44: $1255-1269,2016$

52. Joyce JA and Fearon DT: T cell exclusion, immune privilege, and the tumor microenvironment. Science 348: 74-80, 2015

53. Jenkins RW, Barbie DA and Flaherty KT: Mechanisms of resistance to immune checkpoint inhibitors. Br J Cancer 118: 9-16, 2018.

54. Smyth MJ, Ngiow SF, Ribas A and Teng MW: Combination cancer immunotherapies tailored to the tumour microenvironment. Nat Rev Clin Oncol 13: 143-158, 2016.

55. Ott PA, Hu Z, Keskin DB, Shukla SA, Sun J, Bozym DJ, Zhang W, Luoma A, Giobbie-Hurder A, Peter L, et al: An immunogenic personal neoantigen vaccine for patients with melanoma. Nature 547: 217-221, 2017.

56. Barata PC and Rini BI: Treatment of renal cell carcinoma: Current status and future directions. CA Cancer J Clin 67: 507-524, 2017.

57. Mathew M, Enzler T, Shu CA and Rizvi NA: Combining chemotherapy with PD-1 blockade in NSCLC. Pharmacol Ther 186 : 130-137, 2018

58. Bourgeois-Daigneault MC, Roy DG, Aitken AS, El Sayes N, Martin NT, Varette O, Falls T, St-Germain LE, Pelin A, Lichty BD, et al: Neoadjuvant oncolytic virotherapy before surgery sensitizes triple-negative breast cancer to immune checkpoint therapy. Sci Transl Med 10: pii: eaao1641, 2018.

59. Overman MJ, McDermott R, Leach JL, Lonardi S, Lenz HJ, Morse MA, Desai J, Hill A, Axelson M, Moss RA, et al: Nivolumab in patients with metastatic DNA mismatch repair-deficient or microsatellite instability-high colorectal cancer (CheckMate 142): An open-label, multicentre, phase 2 study. Lancet Oncol 18: 1182-1191, 2017.

60. Chen DS and Mellman I: Oncology meets immunology: The cancer-immunity cycle. Immunity 39: 1-10, 2013.

61. Yshii LM, Hohlfeld R and Liblau RS: Inflammatory CNS disease caused by immune checkpoint inhibitors: Status and perspectives. Nat Rev Neurol 13: 755-763, 2017.

62. Varricchi G, Galdiero MR and Tocchetti CG: Cardiac toxicity of immune checkpoint inhibitors: Cardio-oncology meets immunology. Circulation 136: 1989-1992, 2017.

63. Shoushtari AN, Friedman CF, Navid-Azarbaijani P, Postow MA Callahan MK, Momtaz P, Panageas KS, Wolchok JD and Chapman PB: Measuring toxic effects and time to treatment failure for nivolumab plus ipilimumab in melanoma. JAMA Oncol 4: 98-101, 2018
64. Powles T, Eder JP, Fine GD, Braiteh FS, Loriot Y, Cruz C, Bellmunt J, Burris HA, Petrylak DP, Teng SL, et al: MPDL3280A (anti-PD-L1) treatment leads to clinical activity in metastatic bladder cancer. Nature 515: 558-562, 2014.

65. Mahoney KM, Rennert PD and Freeman GJ: Combination cancer immunotherapy and new immunomodulatory targets. Nat Rev Drug Discov 14: 561-584, 2015.

66. Govindan R, Szczesna A, Ahn MJ, Schneider CP Gonzalez Mella PF, Barlesi F, Han B, Ganea DE, Von Pawel J, Vladimirov V, et al: Phase III trial of ipilimumab combined with paclitaxel and carboplatin in advanced squamous non-small-cell lung cancer. J Clin Oncol 35: 3449-3457, 2017.

67. Reck M, Luft A, Szczesna A, Havel L, Kim SW, Akerley W, Pietanza MC, Wu YL, Zielinski C, Thomas M, et al: Phase III randomized trial of ipilimumab plus etoposide and platinum versus placebo plus etoposide and platinum in extensive-stage small-cell lung cancer. J Clin Oncol 34: 3740-3748, 2016.

68. Lynch TJ, Bondarenko I, Luft A, Serwatowski P, Barlesi F, Chacko R, Sebastian M, Neal J, Lu H, Cuillerot JM, et al: Ipilimumab in combination with paclitaxel and carboplatin as first-line treatment in stage IIIB/IV non-small-cell lung cancer: Results from a randomized, double-blind, multicenter phase II study. J Clin Oncol 30: 2046-2054, 2012.

69. Gubin MM, Zhang X, Schuster H, Caron E, Ward JP, Noguchi T, Ivanova Y, Hundal J, Arthur CD, Krebber WJ, et al: Checkpoint blockade cancer immunotherapy targets tumour-specific mutant antigens. Nature 515: 577-581, 2014.

70. Wolchok JD, Chiarion-Sileni V, Gonzalez R, Rutkowski P, Grob JJ, Cowey CL, Lao CD, Wagstaff J, Schadendorf D, Ferrucci PF, et al: Overall survival with combined nivolumab and ipilimumab in advanced melanoma. N Engl J Med 377: 1345-1356, 2017.

71. Schadendorf D, Larkin J, Wolchok J, Hodi FS, Chiarion-Sileni V, Gonzalez R, Rutkowski P, Grob JJ, Cowey CL, Lao C, et al: Health-related quality of life results from the phase III CheckMate 067 study. Eur J Cancer 82: 80-91, 2017.

72. Hellmann MD, Rizvi NA, Goldman JW, Gettinger SN, Borghaei H, Brahmer JR, Ready NE, Gerber DE, Chow LQ, Juergens RA, et al: Nivolumab plus ipilimumab as first-line treatment for advanced non-small-cell lung cancer (CheckMate 012): Results of an open-label, phase 1, multicohort study. Lancet Oncol 18: 31-41, 2017.

73. Long GV, Atkinson V, Cebon JS, Jameson MB, Fitzharris BM, McNeil CM, Hill AG, Ribas A, Atkins MB, Thompson JA, et al: Standard-dose pembrolizumab in combination with reduced-dose ipilimumab for patients with advanced melanoma (KEYNOTE-029): An open-label, phase 1b trial. Lancet Oncol 18: 1202-1210, 2017.

74. Herrera FG, Bourhis J and Coukos G: Radiotherapy combination opportunities leveraging immunity for the next oncology practice. CA Cancer J Clin 67: 65-85, 2017.

75. Lee JM, Cimino-Mathews A, Peer CJ, Zimmer A, Lipkowitz S, Annunziata CM, Cao L, Harrell MI, Swisher EM,Houston N, et al: Safety and clinical activity of the programmed death-ligand 1 inhibitor durvalumab in combination with poly (ADP-Ribose) polymerase inhibitor olaparib or vascular endothelial growth factor receptor 1-3 inhibitor cediranib in women's cancers: A dose-escalation, phase I study. J Clin Oncol 35: 2193-2202, 2017.

76. Chesney J, Puzanov I, Collichio F, Singh P, Milhem MM, Glaspy J, Hamid O, Ross M, Friedlander P, Garbe C, et al: Randomized, open-label phase II study evaluating the efficacy and safety of talimogene laherparepvec in combination with ipilimumab versus ipilimumab alone in patients with advanced, unresectable melanoma. J Clin Oncol 36: 1658-1667, 2018.

77. Ribas A, Dummer R, Puzanov I, VanderWalde A, Andtbacka RHI, Michielin O, Olszanski AJ, Malvehy J, Cebon J, Fernandez E, et al: Oncolytic virotherapy promotes intratumoral $\mathrm{T}$ cell infiltration and improves anti-PD-1 immunotherapy. Cell 170: 1109-1119, 2017

78. Sender R, Fuchs S and Milo R: Revised estimates for the number of human and bacteria cells in the body. PLoS Biol 14: e1002533, 2016.

79. Hall AB, Tolonen AC and Xavier RJ: Human genetic variation and the gut microbiome in disease. Nat Rev Genet 18: 690-699, 2017.

80. York A: Microbiome: Gut microbiota sways response to cancer immunotherapy. Nat Rev Microbiol 16: 121, 2018.

81. Sivan A, Corrales L, Hubert N, Williams JB, Aquino-Michaels K, Earley ZM, Benyamin FW, Lei YM, Jabri B, Alegre ML, et al: Commensal Bifidobacterium promotes antitumor immunity and facilitates anti-PD-L1 efficacy. Science 350: 1084-1089, 2015. 
82. Vétizou M, Pitt JM, Daillère R, Lepage $P$, Waldschmitt $N$, Flament C, Rusakiewicz S, Routy B, Roberti MP, Duong CP, et al: Anticancer immunotherapy by CTLA-4 blockade relies on the gut microbiota. Science 350: 1079-1084, 2015

83. Routy B, Le Chatelier E, Derosa L, Duong CPM, Alou MT, Daillère R, Fluckiger A, Messaoudene M, Rauber C, Roberti MP, et al: Gut microbiome influences efficacy of PD-1-based immunotherapy against epithelial tumors. Science 359: 91-97, 2018

84. Matson V, Fessler J, Bao R, Chongsuwat T, Zha Y, Alegre ML, Luke JJ and Gajewski TF: The commensal microbiome is associated with anti-PD-1 efficacy in metastatic melanoma patients. Science 359: 104-108, 2018.

85. Gopalakrishnan V, Spencer CN, Nezi L, Reuben A, Andrews MC, Karpinets TV, Prieto PA, Vicente D, Hoffman K, Wei SC, et al: Gut microbiome modulates response to anti-PD-1 immunotherapy in melanoma patients. Science 359: 97-103, 2018.

86. Jobin C: Precision medicine using microbiota. Science 359: 32-34, 2018

87. RodrIguez E, Schetters STT and Van Kooyk Y: The tumour glyco-code as a novel immune checkpoint for immunotherapy. Nat Rev Immunol 18: 204-211, 2018.

88. Van Vliet SJ, Bay S, Vuist IM, Kalay H, García-Vallejo JJ, Leclerc $\mathrm{C}$ and Van Kooyk Y: MGL signaling augments TLR2-mediated responses for enhanced IL-10 and TNF-O secretion. J Leukoc Biol 94: 315-323, 2013.

89. Van Vliet SJ, Gringhuis SI, Geijtenbeek TB and Van Kooyk Y: Regulation of effector $\mathrm{T}$ cells by antigen-presenting cells via interaction of the C-type lectin MGL with CD 45. Nat Immunol 7: 1200-1208, 2006.

90. Drake RR: Glycosylation and cancer: Moving glycomics to the forefront. Adv Cancer Res 126: 1-10, 2015.

91.Pinho SS and Reis CA: Glycosylation in cancer: Mechanisms and clinical implications. Nat Rev Cancer 15: 540-555, 2015.

92. Kaur S, Kumar S, Momi N, Sasson AR and Batra SK: Mucins in pancreatic cancer and its microenvironment. Nat Rev Gastroenterol Hepatol 10: 607-620, 2013.

93. Kim J, Bamlet WR, Oberg AL, Chaffee KG, Donahue G, Cao XJ, Chari S, Garcia BA, Petersen GM and Zaret KS: Detection of early pancreatic ductal adenocarcinoma with thrombospondin-2 and CA19-9 blood markers. Sci Transl Med 9: pii: eaah5583, 2017.

94. Yang AP, Liu J, Lei HY, Zhang QW, Zhao L and Yang GH: CA72-4 combined with CEA, CA125 and CA19-9 improves the sensitivity for the early diagnosis of gastric cancer. Clin Chim Acta 437: 183-186, 2014

95. Ashkani $\mathrm{J}$ and Naidoo KJ: Glycosyltransferase gene expression profiles classify cancer types and propose prognostic subtypes. Sci Rep 6: 26451, 2016

96. Syed P, Gidwani K, Kekki H, Leivo J, Pettersson K and Lamminmäki U: Role of lectin microarrays in cancer diagnosis. Proteomics 16: 1257-1265, 2016.

97. Miles D and Papazisis K: Rationale for the clinical development of STn-KLH (Theratope ${ }^{\circledR}$ ) and anti-MUC-1 vaccines in breast cancer. Clin Breast Cancer 3: S134-S138, 2003.

98. Cagnoni AJ, Pérez Sáez JM, Rabinovich GA and Mariño KV: Turning-off signaling by siglecs, selectins, and galectins: Chemical inhibition of glycan-dependent interactions in cancer. Front Oncol 6: 109, 2016.
99. Posey AD Jr, Schwab RD, Boesteanu AC, Steentoft C, Mandel U, Engels B, Stone JD, Madsen TD, Schreiber K, Haines KM, et al: Engineered CAR T cells targeting the cancer-associated Tn-glycoform of the membrane mucin MUC1 control adenocarcinoma. Immunity 44: 1444-1454, 2016.

100. Unger WW, Mayer CT, Engels S, Hesse C, Perdicchio M, Puttur F, Streng-Ouwehand I, Litjens M, Kalay H, Berod L, et al: Antigen targeting to dendritic cells combined with transient regulatory $\mathrm{T}$ cell inhibition results in long-term tumor regression. Oncoimmunology 4: e970462, 2014.

101. Chou FC, Chen HY, Kuo CC and Sytwu HK: Role of galectins in tumors and in clinical immunotherapy. Int J Mol Sci 1: pii: E430, 2018.

102. Alderton GK: Tumour immunology: TIM3 suppresses antitumour DCs. Nat Rev Immunol 12: 620-621, 2012.

103. Sundar R, Soong R, Cho BC, Brahmer JR and Soo RA: Immunotherapy in the treatment of non-small cell lung cancer. Lung Cancer 85: 101-109, 2014.

104. Anderson AC: Tim-3: An emerging target in the cancer immunotherapy landscape. Cancer Immunol Res 2: 393-398, 2014

105.Liu J, Zhang S, Hu Y, Yang Z, Li J, Liu X, Deng L, Wang Y, Zhang X, Jiang T, et al: Targeting PD-1 and Tim-3 pathways to reverse CD8 T-cell exhaustion and enhance ex vivo T-cell responses to autologous dendritic/tumor vaccines. J Immunother 39: 171-180, 2016.

106. Sakuishi K, Ngiow SF, Sullivan JM, Teng MW, Kuchroo VK, Smyth MJ and Anderson AC: $\mathrm{TIM}^{+} \mathrm{FOXP}^{+}$regulatory T cells are tissue-specific promoters of T-cell dysfunction in cancer. OncoImmunology 2: e23849, 2013.

107. Ngiow SF, von Scheidt B, Akiba H, Yagita H, Teng MW and Smyth MJ: Anti-TIM3 antibody promotes T cell IFN- $\gamma$-mediated antitumor immunity and suppresses established tumors. Cancer Res 71: 3540-3551, 2011.

108.Zhou Q, Munger ME, Veenstra RG, Weigel BJ, Hirashima M, Munn DH, Murphy WJ, Azuma M, Anderson AC, Kuchroo VK, et al: Coexpression of Tim-3 and PD-1 identifies a CD8 ${ }^{+}$ T-cell exhaustion phenotype in mice with disseminated acute myelogenous leukemia. Blood 117: 4501-4510, 2011.

109. Irie A, Yamauchi A, Kontani K, Kihara M, Liu D, Shirato Y, Seki M, Nishi N, Nakamura T, Yokomise H, et al: Galectin-9 as a prognostic factor with antimetastatic potential in breast cancer. Clin Cancer Res 11: 2962-2968, 2005.

110. Fujita K, Iwama H, Sakamoto T, Okura R, Kobayashi K, Takano J, Katsura A, Tatsuta M, Maeda E, Mimura S, et al: Galectin-9 suppresses the growth of hepatocellular carcinoma via apoptosis in vitro and in vivo. Int J Oncol 46: 2419-2430, 2015.

111. Mengshol JA, Golden-Mason L, Arikawa T, Smith M, Niki T, McWilliams R, Randall JA, McMahan R, Zimmerman MA, Rangachari M, et al: A crucial role for Kupffer cell-derived galectin-9 in regulation of $\mathrm{T}$ cell immunity in hepatitis $\mathrm{C}$ infection. PLoS One 5: e9504, 2010.

112. Fujita K, Iwama H, Oura K, Tadokoro T, Samukawa E, Sakamoto T, Nomura T, Tani J, Yoneyama H, Morishita A, et al: Cancer therapy due to apoptosis: Galectin-9. Int J Mol Sci 18: pii: E74, 2017 